Lessons for aspiring authors. For the junior trainee seeking to publish in a high quality journal such as the British Journal of Psychiatry, a case report in the brief reports with an average of 1.2 co-authors is a realistic aim.

To publish a major paper the junior should be prepared to recruit an average of 2.4 co-authors, include a university academic in at least half of his successful submissions, and expect to wait until he is in higher professional training before seeing his name in print.

If, for pressing career reasons or personal vanity, a trainee wishes to be the sole author of a publication he should consider a case report or a literature review.

Holywell Hospital

P. Flanigan

Antrim, N Ireland

\section{The use of yoga with psychiatric patients}

DeAr Sirs

I have received an enquiry from a psychiatrist working in a mental health centre in Israel, enquiring about the use of yoga with psychiatric patients.

For some years an experienced yoga teacher has given class patients attending the Psychiatric Day Hospital here in Southampton. There has been no assessment of the beneficial effects, but it is notable that many patients choose to continue yoga practice after leaving the Day Hospital.

The enquiry prompts me to ask whether any colleagues have experience in the use of yoga with psychiatric patients, and if so whether there is any body of knowledge about the usefulness of this approach, particularly with acute in-patients and psychotic illness.

I should be pleased to put any colleagues with such experience in touch with Dr Weiser.

Pamela M. Ashurst

Department of Psychotherapy and

Psychiatric Day Hospital

Royal South Hants Hospital

Southampton SO9 4PE

\section{Predicting non-attendance}

\section{DeAr Sirs}

Dr Woods' article (Psychiatric Bulletin, January 1992, 16, 18-19) concludes with the suggestion that psychiatrists make incorrect assumptions about patients before seeing them. This may well be true, but it is not demonstrated by the findings he reports.

The study design he used encourages the doctors surveyed to commit themselves to making a judgement about the likelihood of attendance by offering only one neutral respone ("Don't know") out of five possible alternatives. The respondents may have felt obliged to give an opinion even though this is not their usual clinical practice.

In order to reach the conclusion he made the researcher would have had to limit his study to involve only those psychiatrists who claim an ability to predict non-attendance, rather than taking a more general sample. This would have been more meaningful, interesting and informative.

\section{Brynffynnon Child and Family \\ Therapy Clinic \\ Pontypridd \\ Mid-Glamorgan CF37 4DD}

Huw Thomas

\title{
August Bank Holiday
}

The College will be closed from 7.00 p.m. on Thursday, 27 August and will re-open at 8.00 a.m. on Tuesday, 1 September 1992. 